\title{
Novel Approach to Chemotherapy and Administration Selection with Metronomic/Fractionated Dosing
}

\author{
Aaron J. Smith*, John Oertle, Dino Prato \\ Envita, Scottsdale, AZ, USA \\ Email: "Aaron@envita.com
}

Received 22 April 2015; accepted 23 May 2015; published 27 May 2015

Copyright (C) 2015 by authors and Scientific Research Publishing Inc.

This work is licensed under the Creative Commons Attribution International License (CC BY).

http://creativecommons.org/licenses/by/4.0/

(c) (i) Open Access

\begin{abstract}
Metronomic dosing of chemotherapy was introduced in the early 2000 s and has since gained recognition as a potential game changer in the manner of which chemotherapy can be administered. There are several known candidates for metronomic dosing of chemotherapy with the potential for many more to be elucidated in the future. Minimized overall side effects, longer durations of treatment, potential minimization of multidrug resistance (MDR) mutations, potential less refractory responses, and the potential to safely use more than one chemotherapy treatments also make metronomic dosing of chemotherapy attractive. Metronomic dosing reduces common side effects and has the potential to reduce neutropenia, lymphocytopenia, and cognitive changes associated with maximum tolerated dosages (MTD). Methods of enhancing chemotherapy including fasting and administration of insulin are also discussed. Metronomic dosing combined with a patient's molecular profile derived from biomarkers is particularly exciting. It holds significant potential with regard to administrating the most relevant chemotherapies and offers maximal beneficial results.
\end{abstract}

\section{Keywords}

Metronomic Dosing, Chemotherapy, Multidrug Resistance, Neutropenia, Lymphocytopenia, Insulin, Biomarkers, Cognitive Changes

\section{Introduction}

It is our opinion that the dosage of chemotherapy in its current maximum tolerated dose (MTD) may be an oversimplified method of treating cancer. Current standards using MTD essentially focus on what is the highest

\footnotetext{
${ }^{*}$ Corresponding author.
}

How to cite this paper: Smith, A.J., Oertle, J. and Prato, D. (2015) Novel Approach to Chemotherapy and Administration Selection with Metronomic/Fractionated Dosing. Journal of Cancer Therapy, 6, 455-465. 
amount of chemotherapy that can be administered safely in one dose without regard to the potential of better dosing regiments of these drugs. Research has shown that in many cases metronomic dosing has high efficacy and often contributes to better outcomes with lower tendencies toward adverse side effects. This paper will focus on building an argument for metronomic dosing in addition to presenting evidence for ways to enhance the use of metronomic dosing by using genomic targeting such as biomarkers, molecular profiles, patient fasting, and adjunctive insulin shuttling.

\section{Treatment}

\subsection{Metronomic Dosing}

In the year 2000, Fidler and Ellis wrote a paper suggesting that cancer should be treated like a chronic disease, which lends toward a new model of cancer treatment [1]. The name "metronomic therapy" was coined by Douglas Hanahan which described a new kind of dosing regimen of chemotherapy [2]. The practice of metronomic therapy involves low dosage of chemotherapy in equally spaced intervals. Judah Folkman and Robert Kerbel were the first researchers to study the effects of metronomic therapy [3] [4]; demonstrating the efficacy of the approach using several kinds of chemotherapeutic agents. Judah Folkman was also a pioneer in postulating that cancer can be targeted by inhibiting or destroying their blood vessels and pioneered angiogenesis. This new approach allowed for the possibility of treating tumors that are unresponsive to chemotherapy at a maximum dose by targeting cell target switches associated with tumor endothelial cells.

Although metronomic dosing of chemotherapy usually involves a mechanism associated with angiogenesis, there is metronomic dosing that more directly affects the tumor. Gemcitabine and its prodrug LY2334737 show antitumor activity on various kinds of cancers in metronomic dosing. Gemcitabine works by inhibition of DNA synthesis and is taken up into cells by nucleoside transporters and phosphorylated. Inhibition of chain elongation by gemcitabine 5'-triphosphate involves a mechanism where gemcitabine 5'-triphosphate is incorporated directly into the DNA [5]-[8]. LY2334737 first needs to be catabolized by carboxylesterase 2 (CES 2) [9] [10] in the liver, kidneys, and intestines where the amide linkage of valproate is cleaved off of gemcitabine.

Results from experimentation associated with metronomic dosing of gemcitabine and L2334737 showed its efficacy in several kinds of cancer types. Non-small cell lung cancer treated with gemcitabine and LY2334737 in mouse models showed that metronomic dosing of gemcitabine and L2334737 had a greater impact on reducing tumor growth over the controls [11]. More specifically, the tumor inhibition was found in human pleural mesotherlioma tumor PXF 1118 or human squamous NSCLC tumor LXFE 937 with LY2334737 having similar results as the control for LXFE 1422 [11]. In these studies weight loss was less than 6\% and well tolerated with high efficacy and significant tumor reduction on the individuals being treated under metronomic dosing.

An advantage of metronomic dosing of chemotherapy includes the potential to use multiple chemotherapies without inducing significant side effects. Metronomic dosing limits toxicity in chemotherapy and in turn allows for the use of more than one chemotherapy more readily than MTD. LY2334737 and capecitabine were combined in metronomic dosing in mice bearing HCT-116 tumors. The mice were treated once a day with $4 \mathrm{mg} / \mathrm{kg}$ of LY2334737 and the MTD of capecitabine of $175 \mathrm{mg} / \mathrm{kg}$. Each chemotherapy individually showed significant reduction of tumor growth of 50\% to 55\% overall growth respectively compared to the control group [11]. Both chemotherapies given together gave even more significant inhibition of $77 \%$ by the end of the study.

A combination of chemotherapies was also administered to mice containing either HT-29 or CFX to determine whether gavage when taken daily with $150 \mathrm{mg} / \mathrm{kg}$ of capecetabine (MTD), and $6 \mathrm{mg} / \mathrm{kg}$ LY2334737 had a synergistic effect. In mice bearing HT-29 or CXF 676, the monotherapies gave significant antitumor activities while significantly more antitumor properties were observed in vehicle plus LY2334737 [11]. The dual therapies had significantly better antitumor properties than either monotherapy. There was no significant weight loss measured and no deaths were recorded. The combination and the monotherapies were also well tolerated.

Metronomic dosing works in part by inhibiting angiogenesis. Angiogenesis itself is a normal function that occurs naturally in reproduction, development, and tissue repair. However, angiogenesis plays an important role in inflammation, diabetic retinopathy, and tumor formation. Growth and metastatic spread of tumors was also associated with angiogenesis [12]. Angiogenesis is regulated by VEGF and fibroblast growth factor (FGF) receptors and is balanced angiogenesis inhibitors like thrombospondin F (TSP-1) where angiogenic switch occurs when VEGF and FGF levels are high in comparison to TSP-1 [13] [14].

VEGF is an angiogenic poly peptide that is found in many malignant tumors [15]. VEGF is considered a bio- 
marker for angiogenesis in many tumors and is therefore a target in the treatment of cancer [16]-[19]. Metronomic dosage of cyclophosphamide in advanced breast cancer showed a significant decrease in VEGF in patients [20]. VEGF levels were also decreased in aggressive non-small cell carcinoma after treatment with platinum and oral etoposide using a metronomic dosing regimen [21].

Demonstration of certain chemotherapeutic drugs that can be used in metronomic dosing includes the use of cyclophosphamide as an antiangiogenic agent. The use of cyclophosphamide in maximum tolerated dosage (MTD) is well documented. However, when given in shorter intervals and lower dosages, cyclophosphamide showed to have better results than that of the MTD in EMT-6 cell lines [3]. Drug sensitivity was also eradicated in L1210 leukemia and Lewis lung carcinoma when used in metronomic dosing. Although the dosage was lower than the MTD, the animals treated in these experiments required palliative care including to treat gastrointestinal dysfunction and weight loss. Other experiments involving the cyclophosphamide in a metronomic dosing regimen showed the eradication of lymphoma and sarcoma in rat models without reoccurrence or metastatic growth in lymphoma and $83 \%$ of sarcomas. The side effects were mitigated with no weight loss and no toxicities in cardiac, hepatic, and renal toxicities [22].

Other experimentation involving vinblastine in metronomic dosing in vitro showed promising results on neuroblastoma cell lines including SK-NM-C and SK-N-AS. In animal models, neuroblastoma cells were treated by either vinablastine or a monoclonal antibody known to block the function of vascular endothelial growth factor receptor 2 (VEGFR2) or a combination of the two. The drugs by themselves did show some temporary inhibition of tumor growth. When the drugs were taken in combination, the effects involved long term tumor regression. In these experiments, drug toxicity usually signified by weight loss, anorexia, skin tenting, ruffled fur and toxic death were not seen [23].

A diverse number of chemotherapeutics in metronomic dosing were studied with mice who have severe combined immunodeficiency (SCID) including paclitaxel, vinblastine, cisplatin, or doxorubicin either alone or in combination with DC101 [24]. Data showed efficacy in chemo-switching where the standard MTD was followed with metronomic dosing. This data suggest efficacy in a strategy where MTD is followed by maintenance of chemotherapy by metronomic dosing [25].

Metronomic chemotherapy regimens are poorly defined despite a multitude of clinical trials. The appropriate dosing and time periods to obtain maximum results have yet to be elucidated. To better understand what the appropriate dosage and timing of such doses associated with metronomic chemotherapy, angiogenic and vasculogenic biomarkers have been investigated to predict the response of the chemotherapy in patients receiving antiangiogenic treatment [26] [27]. Thus, VEGF and TSP-1 could play a role in the monitoring of treatment activity [28]. It is important to mention that such markers are only a part of a complex system associated with various inducers and inhibitors that are associated with the regulation of angiogenesis [29].

Vasculogenesis describes the progenitor cell-dependent generation of new blood vessels which may also play an important role in the growth and spread of tumors. Circulating endothelial cells (CEC) can be detected in patients vascular, inflammatory and neoplastic conditions but are also demonstrated in some preclinical cancer models [30] [31]. Tumor associated endothelial cells were found to have non-uniform nuclei in some melanoma and liposarcoma xenograft models. Previously, endothelial cells were assumed to not undergo drug resistance because the CECs were thought to be genetically stable [32]. Activated CECs associated with newly formed blood vessels are sensitive to metronomic doses chemotherapeutic drugs including 5-fluoruracil, etoposide, taxanes, doxorubicin, and 4-hydroperoxycyclophosphamide alone or in concert with anti-angiogenic drugs [33][36]. CECs were found to be a surrogate marker for angiogenesis and can be used to evaluate the anti-angiogenic drug activity [37] in addition to selecting drugs at optimal dosage of chemotherapy [38].

Metronomic chemotherapy also has an effect on the immune system in some cases including cyclophosphamide by reducing T-reg cells. This in term reduces the inhibition of T-cells and natural killer cells which restores innate killing activity and peripheral T-cell proliferation when T-reg inhibitory functions are suppressed [39]. Metronomic chemotherapy using cyclophosphamide in nude rats with B-cells lymphoma had sustained tumor regression. Therapeutic effects mediated by the immune system in addition to the effect of tumor angiogenesis supports evidence that the metronomic chemotherapy from these trials involves two mechanisms of action for tumor regression [40].

\subsection{Refractory to Treatment and Genomic Selection of Drug Regimens}

Multiple drug resistance (MDR) describes the phenomenon of resistance to one drug which leads to resistance of 
similar and distinct drugs whose structure and mechanism of action are completely different. Once a term that was used to describe antibiotic resistance [41], the term is now used to describe similar findings in chemotherapy. New chemotherapies are in the process of development to overcome MDR [42]-[46] show some promise in reaching their aims. MDR can be broken down into two forms; acquired or pre-existing. Both forms are certainly problematic for cancer patients trying to find the correct chemotherapy.

One of the mechanisms associated with MDR is drug efflux from cells. Cellular vesicles that eliminate toxins by exocytosis or by promotion of drug efflux have been identified in tumor cells as a mechanism related to MDR. P-glycoprotein is usually found in the plasma membrane and was identified as a transporter of primarily hydrophobic and positively charged toxins [47]. The mechanism is ATP dependent with regard to moving substrates out of the cell. The ABC transport system, comprising of 48 structurally related transporters, are another group of transporters found in cells [48]. Of these 48 structurally related transporters there are three subfamilies. Subfamily B includes P-glycoprotein, subfamily C which includes multi-resistance protein related (MRP) transporters, and subfamily G includes ABCG2, MXR and ABCP proteins. P-glycoproteins are ATP driven and produced particularly in certain cell types including liver, pancreas, kidney, colon, and jejunum. Tumor cell lines with stem cell characteristics have been shown express ABCG2 and MRP1 [49]. Researchers have hypothesized that tumor cells often express drug efflux proteins which is consistent with the previous finding [50] [51]. The efficacy of various anticancer drugs in tumor stem cells can be affected by the expression of drug transporters [52] [53].

It is difficult to tell whether the pre-existing form of MDR is caused by the improper selection of chemotherapies in the first place. There is potential for the use of biomarkers associated with the patient's molecular profile to determine which drugs are more likely to work the first time. Although the exact mechanism for MDR is unknown, postulations with regard to reducing the effect of MDR by metronomic dosing are only beginning to be elucidated. mdr1 gene expression is linked proportionally to the level of drug resistance [54] [55] and an increase in MDR expression is significant in both resistance and cross-resistance of drug sensitive cell lines [56]. Tumor microenvironments are known to induce hypoxia which is the primary driver of ABCB1, ABCC1, and ABCG2 expression [57]-[61]. Therapeutic agents have also been suggested upregulate the expression of these pumps through various signal transduction pathways [62] [63]. These experimentations were conducted using maximum tolerated dosing regiment. There is potential for the use of metronomic dosing in conjunction with a patient's molecular profile to select drugs that have maximum effect without having the significant side effects not to mention MDR. High doses of chemotherapy not only influence cancer cells, but also interact with normal cells that can become resistant to the chemotherapy itself. If any of these exposed and resistant cells become cancerous, one can speculate that there will be a greater opportunity for that kind of cancer to reach MDR at an earlier stage or at the onset.

Cancer stem cells have the potential to have resistance to apoptosis based on acquired changes in apoptotic pathways. Such changes could be inherent in cancer or acquired later in cancer progression. An example involves the inactivation of the p53 gene, loss of expression of PTEN, activation of PI3K, and activation of the RAS/RAF pathway. These activation or deactivation of genes affects pathways that affect the balance of bcl-2 family of proteins respectively [64]. These changes affect the permeability of the out mitochondria and lead to permeability transition [65]. The potential of acquiring these kinds of mutations has an effect on the potential chemotherapy that can be used, thus inducing MDR.

Tumor heterogeneity is also a cause for MDR. Within one tumor, there is potential to be a heterogenic mix of cancer stem cells in particular. This allows resistant cancer stem cells to grow in a niche environment since it is already shielded by a form of MDR. There are a few ways that a tumor can have heterogeneity. The most common are through genetic mutations and/or epigenetic shifts. These changes effect the cancer stem cells' ability to differentiate. These kind of changes can lead to centrosome replication [66] [67] which leads to mitosis, chromosome instability, aneuploidy, and tetraploidy. Microsatalite instability and defective DNA repair mechanisms also have the potential to induce what is known as a mutator phenotype which leads to a large number of genetic variations due to changes in the genetic material [68]. The fact that most cancers are naturally heterogeneous, as well as aneuploidy, may also play a role in resistance respectively.

\subsection{Neutropenia and Lymphocytopenia}

Host protective mechanisms are suppressed by chemotherapy as it affects the hematopoietic system. The most 
serious hematologic toxicity of cancer chemotherapy is neutropenia. Such side effects often limit the amount of chemotherapy that can be administered to a patient. The length and the extent of neutropenia can be used to determine the risk of infection [69] [70]. Suppression of neutrophils and the cytotoxic effect on the alimentary tract predispose cancer patients that undergo chemotherapy to infection. Risk for neutropenia can be either patientspecific or regimen-specific. Patient-specific risk factors include age, comorbid conditions, and type of cancer and disease stage. Hematologic malignancies are known to be a greater risk factor for the development of neutropenia during treatment due to the disease process in addition to the aggressive treatment required. Regimen specific risk factors are intrinsically designated by the kind of chemotherapeutic regimen where some drugs are more myelotoxic than others. Individual chemotherapies that do not significantly affect neutropenia by itself can in combination have a more significant effect than inducing neutropenia.

The condition of having abnormally low levels of lymphocytes in the blood is known as lymphocytopenia. More specifically, lymphocytopenia describes low levels of T lymphocytes, B lymphocytes, and NK lymphocytes. Lymphocytopenia is a common side effect among various types of chemotherapies and can even be caused by the cancer itself. Several chemotherapies have been known to cause lymphocytopenia including temozolomide [71], everolimus [72], bendamustine [73], erlotinib [73], various purine analogs [74], and various cytotoxic chemotherapies [75]. Lymphocytopenia has the potential to reduce the body's own ability to eliminate cancer cells naturally, thus reducing the effectiveness of chemotherapy. However, metronomic dosing of cyclophosphamide in particular induced a selective reduction of regulatory $\mathrm{T}$ cells which in turn can restore innate antitumor activity by mollifying the suppression of cytotoxic T cells and natural killer NK cells [76]. The potential for reducing the effect of lymphocytopenia through metronomic dosing should be explored in order to determine whether or not there is a dose dependent response toward lymphocytopenia during the administration of chemotherapy.

\subsection{The Use of Biomarkers}

Common practice of administering chemotherapy is under the guise of maximum tolerated dose (MTD). In this kind of dosing pattern, the maximum amount of chemotherapy is administered in rounds. This kind of dosing requires a period of recovery for the patient due to the extensive amount of side effects associated with this treatment schedule which can be detrimental to patient response. The drug selection is typically guided by the kind of cancer in addition to elements associated with the tissue biopsy. Biomarkers offer an opportunity to understand how a particular cancer works or how a cell mutated to become cancerous in the first place. Armed with this knowledge, more intelligent selection of chemotherapies can be used to determine which kind of therapy would have the greatest impact on the cancer. The molecular profile describes all the biomarkers associated with a cancer. Knowledge of multiple targets can be used particularly with metronomic dosing to allow the use of more than one chemotherapy to be administered at once. While MTD has the potential to reduce tumor size, there is a high level of relapse and resistance toward the chemotherapy by the tumor in addition to other cells not directly targeted by the round of chemotherapy.

\subsection{Cognitive Changes Induced by Chemotherapy}

Although the mechanism for cognitive changes induced by chemotherapy is for the most part unknown, there are several candidate mechanisms that can offer some light on this issue. The symptoms of chemotherapy induced cognitive changes are subtle and is reflected in executive functions, processing speeds, and various domains of cognition that include working memory [77]-[80] without affecting the retrieval of remote memories [78] [79]. Whereas previous assumptions believed these cognitive changes were related to depression and anxiety or even fatigue, growing research suggests that changes are caused by the chemotherapy themselves. Imaging of patients' brains before and after treatment of chemotherapy show structural and functional changes [81] [82]. However, there are studies that have found that cancer itself can affect cognitive changes before the initiation of chemotherapy [83]-[86] in addition to studies that correlate the diagnosis of cancer as a risk factor for Alzheimer's disease [87].

\subsection{Adjunctive Insulin Shuttling Potentiation}

The effect of insulin to increase cell cycle progression in cancer cells has been documented extensively [88]. 
Insulin's ability to change the phase of the cell cycle to accommodate various chemotherapies that target specific phases of the cell cycle has been documented as a method to potentiate chemotherapies [88]. These insulin potentiated chemotherapies have the potential to be applied in a metronomic dosing regimen in a manner that increases the potency of the chemotherapy while limiting side affects more commonly associated with MTD.

In addition to insulin influencing the cell cycle, early experimentation suggests that insulin also influences the fluidity of the cellular membrane, potentially increasing the opportunity for some chemotherapies to enter the cell less inhibited. Experimentation using liposomes composed primarily of phsophatidyl choline, which is analogous to cellular membranes and also used as a control against membrane proteins that can influence permeability to molecules and elements, showed that there was an increase in glucose permeability in the presence of insulin without GLUT-4 [89]. The experiments showed that there was a two fold increase in glucose permeability in the liposome in the presence of insulin [89]. Although experimentation with regard to increase permeability of chemotherapeutic agents in liposomes in the presence of insulin has not been documented, the increase in fluidity is promising and could potentially add to the documented effects of adjunctive insulin shuttling. Although further studies should be conducted to confirm this hypothesis, insulin affecting the permeability of chemotherapy, additional studies using inverted membrane vesicles (IMV) should also be tested to determine whether insulin increases permeability of glucose and chemotherapies as a more accurate control. As opposed to traditional cellular models, IMV would have the GLUT-4 on the inside of the vesicle so transport of glucose by GLUT-4 would be controlled. The membrane would be significantly more similar to that of cells which would increase the fidelity of the experiments associated with increased permeability of molecules by insulin without using GLUT-4.

\subsection{Fasting}

The inability for cancer cells to acquire key nutrients like glucose has been investigated in vitro and in animal studies. These experiments have shown that lacking key nutrients like glucose has an effect on cellular growth. Reduction and/or the delay of progression of tumor growth has been shown to be as effective as chemotherapy in the reduction or the delaying of tumor progression [90]. This has been documented in glioma, breast cancer cells, and melanoma with regard to the effect of fasting on tumor progression [90]. Augmentation, and in some cases replacing the effectiveness altogether of some chemotherapies for the treatment of various cancers, is caused by fasting in multiple cycles which acts as a method of sensitizing various tumors [90].

\section{Discussion}

Metronomic dosing has potential and should be explored in current drug therapies, in addition to being tested during new drug trials. Although the idea behind metronomic dosing is new, there is a lot of promise surrounding its application in cancer therapy. The opportunity to administer less toxic doses of chemotherapy to evoke the same, and in many cases better outcomes with minimal side effects, should gain more attention among physicians and scientists alike. The significant decrease in side effects may also allow for more chemotherapies to be used to target a given cancer simultaneously. In practice, we have noticed that the use of biomarkers in general to treat cancer suggests the use of newer chemotherapies. These chemotherapies have significantly higher side effects respectively. Although these chemotherapies are targeted and have a higher probability of working for patients, there is potential for the use of metronomic dosing to mitigate or repress the severity of these side effects.

The use of biomarkers to attain a better understanding of a patient's molecular profile is significant and should always be consulted first when starting or trying a new chemotherapeutic agent. However, when available, metronomic dosing should also be used first in order to retain quality of life in addition to maximizing cancer reduction. Other methods to potentiate chemotherapy, including fasting and the use of insulin, are becoming more popular among physicians. These methods should also be considered when administering chemotherapy to patients particularly if the chemotherapeutic agent is one that works at a particular phase of the cell cycle.

The effect of MTD on the immune system is also of significance with regard to quality of life and potentially limiting cancer by immune response. These side effects are significant and can endanger the lives of the patient by exposing the patient to opportunistic infections. Although not studied in metronomic dosing, there is potential to reduce cognitive changes in cancer patients, a significant improvement in quality of life, by the use of metro- 
nomic dosing as compared to the standard MTD schedule.

\section{Conclusion}

Much research needs to be done with regard to establishing optimal dosing regiments for each individual patient to a specific chemotherapy. Of the multitude of chemotherapeutic agents available, there are only a few that have been investigated using metronomic dosing. Advantages of using metronomic dosing include increased tumor reduction and limited side effects as detailed earlier. It is important to consider metronomic dosing when applicable and more information should be available to physicians, fellow scientists, and the public whether a chemotherapy can be used metronomically. The use of biomarkers and metronomic dosing in particular is a very promising combination. Further studies on the efficacy of using several drugs using metronomic dosing should also be investigated further. Other methods including fasting should be more commonly used due to its ability to essentially starve the cancer of key nutrients like glucose during chemotherapy. A significant amount of research needs to be done with regard to adjunctive insulin shuttling but the practice is promising particularly for chemotherapies that target specific phases of the cell cycle. Metronomic dosing is promising and has the potential to offer insight on how chemotherapy should be administered in the present and the future. With advances in immunotherapy, the implications of the immune system response are becoming more evident in the treatment of cancer. Inhibiting the immune response by using MTD has the potential to affect the immune system from targeting cancer cells and ultimately limiting other opportunistic infections.

\section{References}

[1] Fidler, I.J. and Ellis, L.M. (2000) Chemotherapeutic Drugs-More Really Is Not Better. Nature Medicine, 6, 500-502. http://dx.doi.org/10.1038/74969

[2] Hanahan, D., Bergers, G. and Bergsland, E. (2000) Less Is More, Regularly: Metronomic Dosing of Cytotoxic Drugs Can Target Tumor Angiogenesis in Mice. Journal of Clinical Investigation, 105, 1045-1047. http://dx.doi.org/10.1172/JCI9872

[3] Browder, T., Butterfield, C.E., Kräling, B.M., et al. (2000) Antiangiogenic Scheduling of Chemotherapy Improves Efficacy against Experimental Drug-Resistant Cancer. Cancer Research, 60, 1878-1886.

[4] Klement, G., Baruchel, S., Rak, J., et al. (2000) Continuous Low-Dose Therapy with Vinblastine and VEGF Receptor2 Antibody Induces Sustained Tumor Regression without Overt Toxicity. Journal of Clinical Investigation, 105, R15R24. http://dx.doi.org/10.1172/JCI8829

[5] Huang, P., Chubb, S., Hertel, L.W., Grindey, G.B. and Plunkett, W. (1991) Action of 20,20-Difluorodeoxycytidine on DNA Synthesis. Cancer Research, 51, 6110-6117.

[6] Heinemann, V., Xu, Y.-Z., Chubb, S., Sen, A., Hertel, L.W., Grindey, G.B., et al. (1992) Cellular Elimination of 20, 20-Difluorodeoxycytidine 50-Triphosphate: A Mechanism of Self-Potentiation. Cancer Research, 52, 533-539.

[7] Heinemann, V., Xu, Y.-Z., Chubb, S., Sen, A., Hertel, L., G.B.G., et al. (1990) Inhibition of Ribonucleotide Reduction in CCRF-CEM Cells by 20,20-Difluorodeoxycytidine. Molecular Pharmacology, 38, 567-572.

[8] Wang, J., Lohman, G.J.S. and Stubbe, J. (2007) Enhanced Subunit Interactions with Gemcitabine-50-Diphosphate Inhibit Ribonucleotide Reductases. Proceedings of the National Academy of Sciences of the United States of America, 104, 14324-14329. http://dx.doi.org/10.1073/pnas.0706803104

[9] Pratt, S.E., Durland-Busbice, S., Shepard, R.L., Heinz-Taney, K. and Dantzig, A.H. (2013) Human Carboxylesterase 2 Hydrolyzes the Prodrug of Gemcitabine (LY2334737) and Confers Prodrug Sensitivity to Cancer Cells. Clinical Cancer Research, 19, 1159-1168. http://dx.doi.org/10.1158/1078-0432.CCR-12-1184

[10] Sanghani, S., Sanghani, P., Schiel, M. and Bosron, W. (2009) Human Carboxylesterases: An Update on CES1, CES2 and CES3. Protein and Peptide Letters, 16, 1207-1214. http://dx.doi.org/10.2174/092986609789071324

[11] Pratt, S.E., Durland-Busbice, S., Shepard, R.L., Donoho, G.P., Starling, J.J., Wickremsinhe, E.R., Perkins, E.J. and Dantzig, A.H. (2013) Efficacy of Low-Dose Oral Metronomic Dosing of the Prodrug of Gemcitabine, LY2334737, in Human Tumor Xenografts. Molecular Cancer Therapeutics, 4, 481-490. http://dx.doi.org/10.1158/1535-7163.MCT-12-0654

[12] Risau, W. (1997) Mechanisms of Angiogenesis. Nature, 386, 671-674. http://dx.doi.org/10.1038/386671a0

[13] Hanahan, D. and Folkman, J. (1996) Patterns and Emerging Mechanisms of the Angiogenic Switch during Tumorigenesis. Cell, 86, 353-64. http://dx.doi.org/10.1016/S0092-8674(00)80108-7

[14] Lawler, J. (2002) Thrombospondin-1 as an Endogenous Inhibitor of Angiogenesis and Tumor Growth. Journal of Cel- 
lular and Molecular Medicine, 6, 1-12. http://dx.doi.org/10.1111/j.1582-4934.2002.tb00307.x

[15] Salven, P., Mänpää, H., Orpana, A., Alitalo, K. and Joensuu, H. (1997) Serum Vascular Endothelial Growth Factor Is often Elevated in Disseminated Cancer. Clinical Cancer Research, 3, 647-51.

[16] Mainetti, L.E., Rozados, V.R., Bonfil, R.D. and Scharovsky, O.G. (2005) Metronomic Therapy with Cyclophosphamide or Doxorubicin Inhibits Mouse Mammary Adenocarcinoma Growth and Metastasis Development. Proceedings of the American Association for Cancer Research, 46, 1337. www.aacrmeetingabstracts.org/cgi/content/abstract/2005/1/1377-b

[17] Mainetti, L.E., Rozados, V.R., Bonfil, R.D. and Scharovsky, O.G. (2006) Sinergistic Inhibitory Effect of Metronomic Therapy with Oral Cyclophosphamide Combined with a Cox-2 Inhibitor in a Mouse Mammary Adenocarcinoma. Proceedings of the American Association for Cancer Research, 47, 503.

[18] Fersis, N., Smyczek-Gargya, B., Armeanu, S., et al. (2004) Changes in Vascular Endothelial Growth Factor (VEGF) after Chemoendocrine Therapy in Breast Cancer. European Journal of Gynaecological Oncology, 25, 45-50.

[19] Wu, Y.L., Fu, S.L., Zhang, Y.P., Qiao, M.M. and Chen, Y. (2005) Cyclooxygenase-2 Inhibitors Suppress Angiogenesis and Growth of Gastric Cancer Xenografts. Biomedicine \& Pharmacotherapy, 59, S289-S292. http://dx.doi.org/10.1016/S0753-3322(05)80048-4

[20] Colleoni, M., Orlando, L., Sanna, G., et al. (2006) Metronomic Low-Dose Oral Cyclophosphamide and Methotrexate Plus or Minus Thalidomide in Metastatic Breast Cancer: Antitumor Activity and Biological Effects. Annals of Oncology, 17, 232-238. http://dx.doi.org/10.1093/annonc/mdj066

[21] Correale, P., Cerretani, D., Remondo, C., et al. (2006) A Novel Metronomic Chemotherapy Regimen of Weekly Platinum and Daily Oral Etoposide in High-Risk Non-Small Cell Lung Cancer Patients. Oncology Reports, 16, 133-140. http://dx.doi.org/10.3892/or.16.1.133

[22] Rozados, V.R., Sanchez, A.M., Gervasoni, S.I., Berra, H.H., Matar, P. and Scharovsky, O.G. (2004) Metronomic Therapy with Cyclophosphamide Induces Rat Lymphoma and Sarcoma Regression, and Is Devoid of Toxicity. Annals of Oncology, 15, 1543-1550. http://dx.doi.org/10.1093/annonc/mdh384

[23] Klement, G., Baruchel, S., Rak, J., et al. (2000) Continuous Low-Dose Therapy with Vinblastine and VEGF Receptor2 Antibody Induces Sustained Tumor Regression without Overt Toxicity. The Journal of Clinical Investigation, 105, R15-R24. http://dx.doi.org/10.1172/JCI8829

[24] Klement, G., Huang, P., Mayer, B., et al. (2002) Differences in Therapeutic Indexes of Combination Metronomic Chemotherapy and an Anti-VEGFR-2 Antibody in Multidrug-Resistant Human Breast Cancer Xenografts. Clinical Cancer Research, 8, 221-232.

[25] Pietras, K. and Hanahan, D. (2005) A Multitargeted, Metronomic, and Maximum-Tolerated Dose "Chemo-Switch" Regimen Is Antiangiogenic, Producing Objective Responses and Survival Benefit in a Mouse Model of Cancer. Journal of Clinical Oncology, 23, 939-952. http://dx.doi.org/10.1200/JCO.2005.07.093

[26] Mancuso, P., Burlini, A., Pruneri, G., Goldhirsch, A., Martinelli, G. and Bertolini, F. (2001) Resting and Activated Endothelial Cells Are Increased in the Peripheral Blood of Cancer Patients. Blood, 97, 3658-3661. http://dx.doi.org/10.1182/blood.V97.11.3658

[27] Rabascio, C., Muratori, E., Mancuso, P., et al. (2004) Assessing Tumor Angiogenesis: Increased Circulating Ve-Cadherin RNA in Patients with Cancer Indicates Viability of Circulating Endothelial Cells. Cancer Research, 64, 43734377. http://dx.doi.org/10.1158/0008-5472.CAN-04-0265

[28] Dudek, A.Z. and Mahaseth, H. (2005) Circulating Angiogenic Cytokines in Patients with Advanced Non-Small Cell Lung Cancer: Correlation with Treatment Response and Survival. Cancer Investigation, 23, 193-200. http://dx.doi.org/10.1081/CNV-200055949

[29] Stempak, D., Gammon, J., Halton, J., Moghrabi, A., Koren, G. and Baruchel, S. (2006) A Pilot Pharmacokinetic and Antiangiogenic Biomarker Study of Celecoxib and Low-Dose Metronomic Vinblastine or Cyclophosphamide in Pediatric Recurrent Solid Tumors. Journal of Pediatric Hematology/Oncology, 28, 720-728. http://dx.doi.org/10.1097/01.mph.0000243657.64056.c3

[30] Monestiroli, S., Mancuso, P., Burlini, A., Pruneri, G., Dell’Agnola, C., Gobbi, A., Martinelli, G. and Bertonlini, F. (2001) Kinetics and Viability of Circulating Endothelial Cells as Surrogate Angiogenesis Marker in an Animal Model of Human Lymphoma. Cancer Research, 61, 4341-4344.

[31] Capillo, M., Mancuso, P., Gobbi, A., Monestiroli, S., Pruneri, G., Dell’Agnola, C., Martinelli, G., Shultz, L. and Bertolini, F. (2003) Continuous Infusion of Endostatin Inhibits Differentiation, Mobilization and Clonogenic Potential of Endothelial Cell Progenitors. Clinical Cancer Research, 9, 377-382.

[32] Kerbel, R.S. (1991) Inhibition of Tumor Angiogenesis as a Strategy to Circumvent Acquired Resistance to Anti-Cancer Therapeutic Agents. BioEssays, 13, 31-36. http://dx.doi.org/10.1002/bies.950130106

[33] Klement, G., Huang, P., Mayer, B., Green, S.K., Man, S., Bohlen, P., Hicklin, D. and Kerbel, R.S. (2002) Differences 
in Therapeutic Indexes of Combination Metronomic Chemotherapy and an Anti-VEGFR-2 Antibody in MultidrugResistant Human Breast Cancer Xenografts. Clinical Cancer Research, 8, 221-232.

[34] Asahara, T., Takahashi, T., Masuda, H., Kalka, C., Chen, D., Iwaguro, H., Inai, Y., Silver, M. and Isner, J.M. (1999) VEGF Contributes to Postnatal Neovascularization by Mobilizing Bone Marrow-Derived Endothelial Progenitor Cells. The EMBO Journal, 18, 3964-3972. http://dx.doi.org/10.1093/emboj/18.14.3964

[35] Twardowski, P.W., Smith-Powell, L., Carroll, M., VanBalgooy, J., Ruel, C., Frankel, P. and Synold, T.W. (2008) Biologic Markers of Angiogenesis: Circulating Endothelial Cells in Patients with Advanced Malignancies Treated on Phase I Protocol with Metronomic Chemotherapy and Celecoxib. Cancer Investigation, 26, 53-59. http://dx.doi.org/10.1080/07357900701681541

[36] Bocci, G., Nicolaou, K.C. and Kerbel, R.S. (2002) Protracted Low-Dose Effects on Human Endothelial Cell Proliferation and Survival in Vitro Reveal a Selective Antiangiogenic Window for Various Chemotherapeutic Drugs. Cancer Research, 62, 6938-6943.

[37] Shaked, Y., Bertolini, F., Man, S., Rogers, M.S., Cervi, D., Foutz, T., Rawn, K., Voskas, D., Dumont, D.J., Ben-David, Y., Layler, J., Henkin, J., Huber, J., Hicklin, D.J., D’Amato, R.J. and Kerbel, R.S. (2005) Genetic Heterogeneity of the Vasculogenic Phenotype Parallels Angiogenesis; Implications for Cellular Surrogate Marker Analysis of Antiangiogenesis. Cancer Cell, 7, 101-111.

[38] Shaked, Y., Emmenegger, U., Man, S., Cervi, D., Bertolini, F., Ben-David, Y. and Kerbel, R.S. (2005) The Optimal Biological Dose of Metronomic Chemotherapy Regimens Is Associated with Maximum Antiangiogenic Activity. Blood, 106, 3058-3061. http://dx.doi.org/10.1182/blood-2005-04-1422

[39] Jimenez, B., Volpert, O.V., Crawford, S.E., Febbraio, M., Silverstein, R.L. and Bouck, N. (2000) Signals Leading to Apoptosis-Dependent Inhibition of Neovascularization by Thrombospondin-1. Nature Medicine, 6, 41-48. http://dx.doi.org/10.1038/71517

[40] Rozados, V.R., Mainetti, L.E., Rico, M.J., Zacarías Fluck, M.F., Matar, P. and Scharovsky, O.G. (2007) Antiangiogenic and Inmunomodulatory Effect of the Metronomic Therapy with Cyclophosphamide [Abstract]. Biocell, 3, 119.

[41] Bolhuis, H., Van Veen, H.W., Poolman, B., Driessen, A.J. and Konings, W.N. (1997) Mechanisms of Multidrug Transporters. FEMS Microbiology Reviews, 21, 55-84. http://dx.doi.org/10.1111/j.1574-6976.1997.tb00345.x

[42] Kawase, M. and Motohashi, N. (2003) New Multidrug Resistance Reversal Agents. Current Drug Targets, 4, 31-43. http://dx.doi.org/10.2174/1389450033347064

[43] Szakacs, G., Paterson, J.K., Ludwig, J.A., Booth-Genthe, C. and Gottesman, M.M. (2006) Targeting Multidrug Resistance in Cancer. Nature Reviews Drug Discovery, 5, 219-234. http://dx.doi.org/10.1038/nrd1984

[44] Ozben, T. (2006) Mechanisms and Strategies to Overcome Multiple Drug Resistance in Cancer. FEBS Letters, 580, 2903-2909. http://dx.doi.org/10.1016/j.febslet.2006.02.020

[45] Dubikovskaya, E.A., Thorne, S.H., Pillow, T.H., Contag, C.H. and Wender, P.A. (2008) Overcoming Multidrug Resistance of Small-Molecule Therapeutics through Conjugation with Releasable Octaarginine Transporters. Proceedings of the National Academy of Sciences of the United States of America, 105, 12128-12133. http://dx.doi.org/10.1073/pnas.0805374105

[46] Baguley, B.C. (2010) Multidrug Resistance in Cancer. Methods in Molecular Biology, 596, 1-14. http://dx.doi.org/10.1007/978-1-60761-416-6_1

[47] Ling, V. (1997) Multidrug Resistance: Molecular Mechanisms and Clinical Relevance. Cancer Chemotherapy and Pharmacology, 40, S3-S8. http://dx.doi.org/10.1007/s002800051053

[48] Gillet, J.P., Efferth, T. and Remacle, J. (2007) Chemotherapy-Induced Resistance by ATP-Binding Cassette Transporter Genes. Biochimica et Biophysica Acta, 1775, 237-262.

[49] Ejendal, K.F. and Hrycyna, C.A. (2002) Multidrug Resistance and Cancer: The Role of the Human ABC Transporter ABCG2. Current Protein \& Peptide Science, 3, 503-511. http://dx.doi.org/10.2174/1389203023380521

[50] Sarkadi, B., Ozvegy-Laczka, C., Nemet, K. and Varadi, A. (2004) ABCG2-A Transporter for All Seasons. FEBS Letters, 567, 116-120. http://dx.doi.org/10.1016/j.febslet.2004.03.123

[51] Loebinger, M.R., Giangreco, A., Groot, K.R., Prichard, L., Allen, K., Simpson, C., Bazley, L., Navani, N., Tibrewal, S., Davies, D. and Janes, S.M. (2008) Squamous Cell Cancers Contain a Side Population of Stem-Like Cells That Are Made Chemosensitive by ABC Transporter Blockade. British Journal of Cancer, 98, 380-387. http://dx.doi.org/10.1038/sj.bjc.6604185

[52] Hadnagy, A., Gaboury, L., Beaulieu, R. and Balicki, D. (2006) SP Analysis May Be Used to Identify Cancer Stem Cell Populations. Experimental Cell Research, 312, 3701-3710. http://dx.doi.org/10.1016/j.yexcr.2006.08.030

[53] Keshet, G.I., Goldstein, I., Itzhaki, O., Cesarkas, K., Shenhav, L., Yakirevitch, A., Treves, A.J., Schacter, J., Amariglio, N. and Rechavi, G. (2008) MDR1 Expression Identifies Human Melanoma Stem Cells. Biochemical and Biophysical 
Research Communications, 368, 930-936. http://dx.doi.org/10.1016/j.bbrc.2008.02.022

[54] Roninson, I.B., Abelson, H.T., Housman, D.E., Howell, N. and Varshavsky, A. (1984) Amplification of Specific DNA Sequences Correlates with Multi-Drug Resistance in Chinese Hamster Cells. Nature, 309, 626-628. http://dx.doi.org/10.1038/309626a0

[55] Roninson, I.B. (1983) Detection and Mapping of Homologous, Repeated and Amplified DNA Sequences by DNA renaturation in Agarose Gels. Nucleic Acids Research, 11, 5413-5431.

[56] Gros, P., Croop, J., Roninson, I., Varshavsky, A. and Housman, D.E. (1986) Isolation and Characterization of DNA Sequences Amplified in Multidrug-Resistant Hamster Cells. Proceedings of the National Academy of Sciences of the United States of America, 83, 337-341. http://dx.doi.org/10.1073/pnas.83.2.337

[57] Comerford, K.M., Wallace, T.J., Karhausen, J., Louis, N.A., Montalto, M.C. and Colgan, S.P. (2002) Hypoxia-Inducible Factor-1-Dependent Regulation of the Multidrug Resistance (MDR1) Gene. Cancer Research, 62, 3387-3394.

[58] Liu, L., Ning, X., Sun, L., Zhang, H., Shi, Y., Guo, C., Han, S., Liu, J., Sun, S., Han, Z., Wu, K. and Fan, D. (2008) Hypoxiainducible Factor-1 Alpha Contributes to Hypoxia-Induced Chemoresistance in Gastriccancer. Cancer Science, 99, 121-128.

[59] Han, H.K., Han, C.Y., Cheon, E.P., Lee, J. and Kang, K.W. (2007) Role of Hypoxia-Inducible Factoralpha in Hepatitis-B-Virus X Protein-Mediated MDR1 Activation. Biochemical and Biophysical Research Communications, 357, 567573. http://dx.doi.org/10.1016/j.bbrc.2007.04.012

[60] Song, X., Liu, X., Chi, W., Liu, Y., Wei, L., Wang, X. and Yu, J. (2006) Hypoxiainduced Resistance to Cisplatin and Doxorubicin in Non-Small Cell Lung Cancer Is Inhibited by Silencing of HIF-1 Alpha Gene. Cancer Chemotherapy and Pharmacology, 58, 776-784. http://dx.doi.org/10.1007/s00280-006-0224-7

[61] Krishnamurthy, P., Ross, D.D., Nakanishi, T., Bailey-Dell, K., Zhou, S., Mercer, K.E., Sarkadi, B., Sorrentino, B.P. and Schuetz, J.D. (2004) The Stem Cell Marker Bcrp/ABCG2 Enhances Hypoxic Cell Survival through Interactions with Heme. The Journal of Biological Chemistry, 279, 24218-24225. http://dx.doi.org/10.1074/jbc.M313599200

[62] Kohno, K., Sato, S., Takano, H., Matsuo, K. and Kuwano, M. (1989) The Direct Activation of Human Multidrug Resistance Gene (MDR1) by Anticancer Agents. Biochemical and Biophysical Research Communications, 165, 14151421. http://dx.doi.org/10.1016/0006-291X(89)92761-7

[63] Chaudhary, P.M. and Roninson, I.B. (1993) Induction of Multidrug Resistance in Human Cells by Transient Exposure to Different Chemotherapeutic Drugs. Journal of the National Cancer Institute, 85, 632-639. http://dx.doi.org/10.1093/jnci/85.8.632

[64] Danial, N.N. (2007) BCL-2 Family Proteins: Critical Checkpoints of Apoptotic Cell Death. Clinical Cancer Research, 13, 7254-7263. http://dx.doi.org/10.1158/1078-0432.CCR-07-1598

[65] Forte, M. and Bernardi, P. (2006) The Permeability Transition and BCL-2 Family Proteins in Apoptosis: Co-Conspirators or Independent Agents? Cell Death and Differentiation, 13, 1287-1290. http://dx.doi.org/10.1038/sj.cdd.4401957

[66] Kramer, A., Lukas, J. and Bartek, J. (2004) Checking Out the Centrosome. Cell Cycle, 3, 1390-1393. http://dx.doi.org/10.4161/cc.3.11.1252

[67] McDermott, K.M., Zhang, J., Holst, C.R., Kozakiewicz, B.K., Singla, V. and Tlsty, T.D. (2006) p16 ${ }^{\mathrm{INK} 4 \mathrm{a}}$ Prevents Centrosome Dysfunction and Genomic Instability in Primary Cells. PLoS Biology, 4, e51. http://dx.doi.org/10.1371/journal.pbio.0040051

[68] Loeb, L.A., Bielas, J.H. and Beckman, R.A. (2008) Cancers Exhibit a Mutator Phenotype: Clinical Implications. Cancer Research, 68, 3551-3557. http://dx.doi.org/10.1158/0008-5472.CAN-07-5835

[69] Bodey, G.P., Buckley, M., Sathe, Y.S. and Freireich, E.J. (1966) Quantitative Relationships between Circulating Leukocytes and Infection in Patients with Acute Leukemia. Annals of Internal Medicine, 64, 328-340. http://dx.doi.org/10.7326/0003-4819-64-2-328

[70] Blackwell, S. and Crawford, J. (1994) Filgrastim (r-metHuG-CSF) in the Chemotherapy Setting. In: Morstyn, G., Dexter, T.M. and Foote, M., Eds., Filgrastim (r-metHuG-CSF) in Clinical Practice, Marcel Dekker, New York, 103-106.

[71] Su, Y.B., Sohn, S., Krown, S.E., et al. (2004) Selective CD4 ${ }^{+}$Lymphopenia in Melanoma Patients Treated with Temozolomide: A Toxicity with Therapeutic Implications. Journal of Clinical Oncology, 22, 610-616. http://dx.doi.org/10.1200/JCO.2004.07.060

[72] Amato, R. and Stepankiw, M. (2013) Evaluation of Everolimus in Renal Cell Cancer. Drug Evaluations, 14, 12291240. http://dx.doi.org/10.1517/14656566.2013.791677

[73] Layman, R.M., Ruppert, A.S., Lynn, M., Mrozek, E., Ramaswamy, B., Lustberg, M., Wesolowski, R., Ottman, S., Carthers, S., Bingman, A., Reinbolt, R., Kraut, E.H. and Shapiro, C.L. (2013) Severe and Prolonged Lymphopenia Observed in Patients Treated with Bendamustine and Erlotinib for Metastatic Triple Negative Breast Cancer. Cancer Chemotherapy and Pharmacology, 71, 1183-1190. http://dx.doi.org/10.1007/s00280-013-2112-2 
[74] Dighiero, G. (1996) Adverse and Beneficial Immunological Effects of Purine Nucleoside Analogs. Hematology and Cell Therapy, 38, S75-S81

[75] Ray-Coquard, I., Borg, C., Bachelot, T., Sebban, C., Phillip, I., Clapisson, G., Le Cesne, A., Biron, P., Chauvin, F. and Blay, J.Y. (2003) Baseline and Early Lymphopenia Predict for the Risk of Febrile Neutropenia after Chemotherapy. British Journal of Cancer, 88, 181-186. http://dx.doi.org/10.1038/sj.bjc.6600724

[76] Ghiringhelli, F., Menard, C., Puig, P.E., et al. (2007) Metronomic Cyclophosphamide Regimen Selectively Depletes $\mathrm{CD} 4{ }^{+} \mathrm{CD} 25^{+}$Regulatory T Cells and Restores T and NK Effector Functions in End Stage Cancer Patients. Cancer Immunology, Immunotherapy, 56, 641-648. http://dx.doi.org/10.1007/s00262-006-0225-8

[77] Tannock, I.F., Ahles, T.A., Ganz, P.A. and van Dam, F.S. (2004) Cognitive Impairment Associated with Chemotherapy for Cancer: Report of a Workshop. Journal of Clinical Oncology, 22, 2233-2239. http://dx.doi.org/10.1200/JCO.2004.08.094

[78] Ahles, T.A. and Saykin, A.J. (2002) Breast Cancer Chemotherapy-Related Cognitive Dysfunction. Clinical Breast Cancer, 3, S84-S90. http://dx.doi.org/10.3816/CBC.2002.s.018

[79] Ferguson, R.J. and Ahles, T.A. (2003) Low Neuropsychologic Performance among Adult Cancer Survivors Treated with Chemotherapy. Current Neurology and Neuroscience Reports, 3, 215-222. http://dx.doi.org/10.1007/s11910-003-0081-2

[80] Anderson-Hanley, C., Sherman, M.L., Riggs, R., Agocha, V.V. and Compas, B.E. (2003) Neuropsychological Effects of Treatments for Adults with Cancer: A Meta-Analysis and Review of the Literature. Journal of the International Neuropsychological Society, 9, 967-982. http://dx.doi.org/10.1017/s1355617703970019

[81] Saykin, A.J., Ahles, T.A. and McDonald, B.C. (2003) Mechanisms of Chemotherapy-Induced Cognitive Disorders: Neuropsychological, Pathophysiological and Neuroimaging Perspectives. Seminars in Clinical Neuropsychiatry, 8, 201-216.

[82] Stemmer, S., Stears, J.C., Burton, B.S., et al. (1994) White Matter Changes in Patients with Breast Cancer Treated with High-Dose Chemotherapy and Autologous Bone Marrow Support. American Journal of Neuroradiology, 15, 12671273.

[83] Wefel, J.S., Lenzi, R., Theriault, R., et al. (2004) “Chemobrain” in Breast Carcinoma? A Prologue. Cancer, 101, 466475. http://dx.doi.org/10.1002/cncr.20393

[84] Meyers, C.A., Albitar, M. and Estey, E. (2005) Cognitive Impairment, Fatigue, and Cytokine Levels in Patients with Acute Myelogenous Leukemia or Myelodysplastic Syndrome. Cancer, 104, 788-793. http://dx.doi.org/10.1002/cncr.21234

[85] Ahles, T.A., Silberfarb, P.M., Maurer, L.H., et al. (1998) Psychological and Neuropsychological Functioning of Patients with Limited Smallcell Lung Cancer Treated with Chemotherapy and Radiation Therapy with or without Warfarin, a Study for Cancer and Leukemia Group B. Journal of Clinical Oncology, 16, 1954-1960.

[86] Wagner, L.I., Sweet, J.J., Butt, Z., et al. (2006) Trajectory of Cognitive Impairment during Breast Cancer Treatment: A Prospective Analysis. Journal of Clinical Oncology, 24, 8500.

[87] Heflin, L.H., Meyerowitz, B.E., Hall, P., et al. (2005) Cancer as a Risk Factor for Long-Term Cognitive Deficits and Dementia. Journal of the National Cancer Institute, 97, 854-856. http://dx.doi.org/10.1093/jnci/dji137

[88] Smith, A.J., Oertle, J. and Prato, D. (2015) Genetically Targeted Fractionated Chemotherapy. Journal of Cancer Therapy, 6, 182-198. http://dx.doi.org/10.4236/jct.2015.62021

[89] Kafka, M.S. (1974) The Effect of Insulin on the Permeability of Phosphatidyl Choline Bimolecular Membranes to Glucose. The Journal of Membrane Biology, 18, 81-94. http://dx.doi.org/10.1007/BF01870104

[90] Lee, C., Raffaghello, L., Brandhorst, S., Safdie, F.M., Bianchi, G., Martin-Montalvo, A., Pistoia, V., Wei, M., Hwang, S., Merlino, A., Emionite, L., Cabo, R. and Longo, V. (2012) Fasting Cycles Retard Growth of Tumor and Sensitize a Range of Cancer Cell Types to Chemotherapy. Science Translational Medicine, 4, 124ra27. 